\title{
GDM Alters Expression of Placental Estrogen Receptor $\alpha$ in a Cell Type and Gender-Specific Manner
}

Reproductive Sciences

2015, Vol. 22(I2) 1488-1495

(C) The Author(s) 2015

Reprints and permission:

sagepub.com/journalsPermissions.nav DOI: I0.II77/I9337|9|I5585I47

rs.sagepub.com

(S)SAGE

\author{
Julia Knabl, MD ${ }^{1,2}$, Ursula Hiden, PhD ${ }^{1,3}$, Rebecca Hüttenbrenner', \\ Christina Riedel, $M \mathrm{Sc}^{1,4}$, Stefan Hutter, MD', Verena Kirn, MD ${ }^{1,5}$, \\ Margit Günthner-Biller, MD', Gernot Desoye, $\mathbf{P h D}^{1,3}$, \\ Franz Kainer, $M D^{1,2}$, and Udo Jeschke, PhD' $^{\prime}$
}

\begin{abstract}
Objective: The nuclear receptor estrogen receptor $\alpha(E R \alpha)$ is one of the key players in energy balance, insulin resistance, and trophoblast differentiation. We tested the hypothesis that gestational diabetes mellitus (GDM) alters expression of placental ER $\alpha$ in a cell type-specific manner and that this regulation may involve epigenetic changes. Study Design: Expression of ER $\alpha$ was analyzed by immunohistochemistry using the semiquantitative immunoreactive score in 80 placentas (40 GDM/40 controls). Quantitative real-time polymerase chain reaction (PCR) measured ER $\alpha$ messenger RNA (mRNA) in decidual tissue. Methylationspecific PCR was performed to analyze cytosine-phosphatidyl-guanine-island methylation of the ER $\alpha$ promoter. Results: Expression of $E R \alpha$ protein is upregulated $(P=.0 \mathrm{II})$ in GDM in extravillous trophoblasts but not in syncytiotrophoblast. Gestational diabetes mellitus downregulated $E R \alpha$ in decidual vessels only in pregnancies with male but not female fetuses. Furthermore, mRNA of the ER $\alpha$ encoding gene estrogen receptor gene I (ESRI) was increased (+I.77 fold) in GDM decidua when compared to controls $(P=.024)$. In parallel, the promoter of ESRI was methylated only in decidua of healthy control individuals but not in GDM. Conclusion: Gestational diabetes mellitus affects expression of placental ER $\alpha$ in a cell typedependent way, on epigenetic level. These data link GDM with epigenetic deregulations of ER $\alpha$ expression and open new insights into the intrauterine programming hypothesis of GDM.
\end{abstract}

\section{Keywords}

gestational diabetes, estrogen, nuclear receptor, methylation, trophoblast

\section{Introduction}

Estrogens exert a great variety of actions in almost every cell type and through diverse cellular and molecular pathways. Activation of intracellular estrogen receptors (ERs) induces their translocation into the nucleus where they act as transcription factors by binding to the estrogen response element, thus regulating gene transcription. ${ }^{1}$

The ERs, ER $\alpha$ and ER $\beta$, encoded by the ESR 1 and estrogen receptor gene 2 (ESR2) gene, have been both involved in energy balance, ${ }^{2}$ although evidence indicates $\operatorname{ER} \alpha$ as the main mediator: Knockout of $\mathrm{ER} \alpha$ as well as of the estrogensynthesizing enzyme aromatase in mice results in obesity and insulin resistance. ${ }^{3,4}$ Especially, ER $\alpha$ is related to glucose uptake and metabolism in different tissues including skeletal muscle, adipose tissue, liver, brain, and endocrine pancreas. ${ }^{5}$ Besides these classical insulin target tissues, ER $\alpha$ is expressed also in maternal and fetal parts of the placenta. However, the exact function of ER $\alpha$ in this organ is yet to be identified. Transcriptional regulation of the leptin gene by ER $\alpha$ in the placental syncytiotrophoblast (SCT) ${ }^{6}$ suggests a role of ER $\alpha$ in hormonal regulation of metabolism.

Gestational diabetes mellitus (GDM) is defined as glucose intolerance first diagnosed during pregnancy. It is characterized by insulin resistance with insulin levels insufficient to compensate the increased demand. ${ }^{7}$ Between $5 \%$ and $15 \%$ of

\footnotetext{
I Department of Obstetrics and Gynecology, Ludwig Maximilians Universität München, Campus Innenstadt, Munich, Germany

${ }^{2}$ Klinik Hallerwiese, Department of Obstetrics, Nuremberg, Germany

${ }^{3}$ Department of Obstetrics and Gynecology, Medical University Graz, Graz, Austria

${ }^{4}$ Institut für Soziale Pädiatrie und Jugendmedizin, Ludwig-Maximilians-Universität München, Munich, Gemany

${ }^{5}$ Department of Obstetrics and Gynecology, University Hospital of Cologne, Cologne, Germany
}

\section{Corresponding Author:}

Udo Jeschke, Department of Obstetrics and Gynecology, Ludwig-Maximilians Universitat Munchen, Maistr.I I, 80337 Munich, Germany.

Email: udo.jeschke@med.uni-muenchen.de 
Table I. Clinical Details of the Patients With Gestational Diabetes Mellitus (GDM) and of the Normal Control Group (Mean \pm SD).

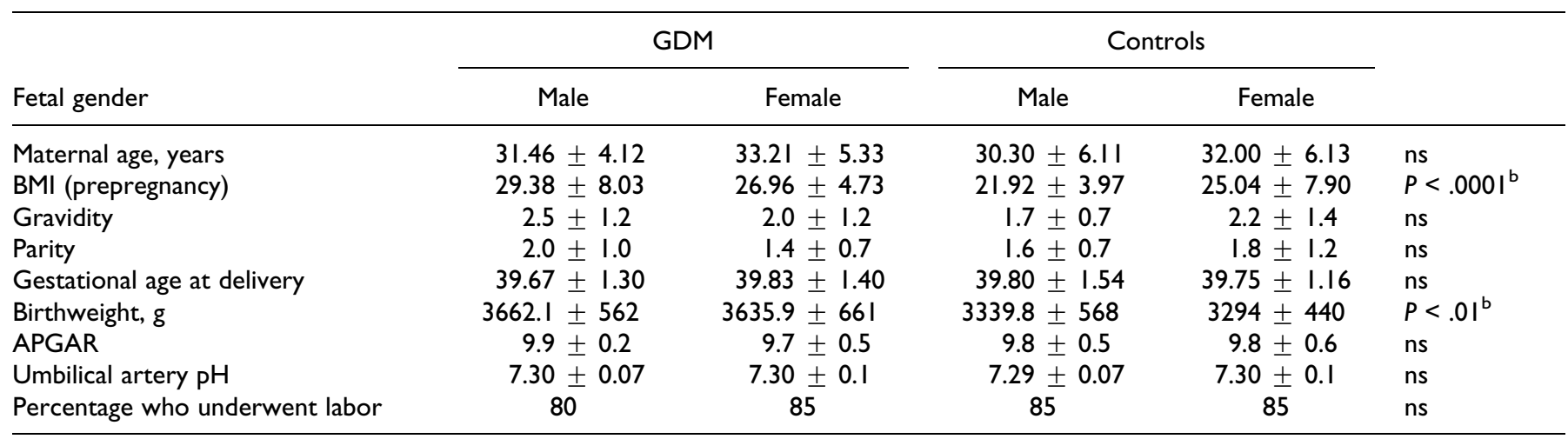

Abbreviations: SD, standard deviation; BMI, body mass index.

${ }^{\mathrm{a}}$ The Kruskal-wallis test was applied to compare clinical outcome data of the groups.

${ }^{\mathrm{b}} P$ values which are statistically significant.

all pregnancies are currently affected by $\mathrm{GDM}^{8}$ As a consequence of the worldwide obesity epidemic, GDM prevalence is further rising. ${ }^{9}$ Gestational diabetes mellitus is associated with short- and long-term complications for the offspring: Shortterm consequences include perinatal complications due to high birth weight and fetal hyperinsulinemia. ${ }^{10,11}$ Long-term consequences include a higher risk to develop obesity, metabolic syndrome, and type 2 diabetes in later life. ${ }^{12}$ Epidemiologic studies and animal experiments link the susceptibility for these metabolic diseases in the offspring to epigenetic changes by the diabetic environment in utero. ${ }^{13,14}$ Chromatin modifications due to DNA methylation are one of the underlying mechanisms for intrauterine programming by causing persistent changes in gene expression. ${ }^{15}$ Methylation of cytosine-phosphatidyl-guanine $(\mathrm{CpG})$ sites within the promoter region of certain genes can reduce gene expression ${ }^{16-19}$ and, vice versa, hypomethylation of promoter regions allows increased gene expression. ${ }^{20}$

The placenta is a fetal organ and exposed to the same intrauterine environment as the fetus. In a pregnancy complicated by GDM, the placenta is affected by maternal metabolic derangements. Due to its critical role in fetal growth and nutrient exchange, the placenta is a great model to study epigenetic changes in metabolic programming in fetal life. ${ }^{15}$ Gestational diabetes mellitus has epigenetic effects on genes preferentially involved in metabolic disease pathways, supporting the notion that DNA methylation is involved in fetal metabolic programming. ${ }^{9,21-24}$ The placenta is one of the tissues in which GDM alters methylation. ${ }^{25,26}$

The known regulation of the leptin gene by ER $\alpha$ in the placental SCT in parallel with increased leptin levels in GDM prompted us to hypothesize changes in placental expression of $E R \alpha$ in GDM and that these changes may result from methylation changes of the ESR1 promoter region.

\section{Materials and Methods}

The study was approved by the ethics committee of the LudwigMaximilian-University (LMU) Munich, Germany, and written informed consent was obtained from the patients. Placental tissue was obtained from 80 women. All women underwent an oral glucose tolerance test ${ }^{27}$ at weeks 24 to 28 of gestation. According to the criteria of the German Diabetes Society (capillary whole blood; fasting glucose $>90 \mathrm{mg} / \mathrm{dL}, 1$ hour $>180 \mathrm{mg} /$ $\mathrm{dL}, 2$ hours $>155 \mathrm{mg} / \mathrm{dL}$; GDM was defined with 2 values above this limits), 40 women were diagnosed with GDM. Immediately after delivery, the samples were taken from the central part of the placenta. In addition, a cotyledon structure showing sufficient blood supply was chosen. Calcified, necrotic, and visually ischemic areas were excluded from collection. Two pieces (2 $\times 2 \times 2$ centimeter) were dissected, containing decidua, extravillous, and villous trophoblasts. Each sample was divided in 2 parts. One part was further separated into decidual and villous tissue, frozen separately, and stored at $-80^{\circ} \mathrm{C}$. A second part of placental tissue was fixed in $4 \%$ buffered formalin for 24 hours and thereafter embedded in paraffin. Thus, immunohistochemistry, gene expression, and DNA methylation analysis were performed with tissues from the same sampling site.

All patients in the GDM group were treated with insulin. The patients were monitored at least once a week at the Diabetes Center of the Department of Internal Medicine, LMU; $75 \%$ of patients were under good glycemic control according to their mean blood glucose. Demographic and clinical data of the study population are summarized in Table 1. Perinatal and clinical data of the study group were published recently. ${ }^{28}$

\section{Immunohistochemistry}

Sections were dewaxed in xylol (20 minutes), and endogenous peroxidase was quenched with $3 \%$ hydrogen peroxide (Merck, Darmstadt, Germany) in methanol (20 minutes). Following rehydration in a descending series of alcohol, epitope retrieval was performed in a pressure cooker ( 5 minutes) using sodium citrate buffer $(0.1 \mathrm{~mol} / \mathrm{L}$ citric acid $/ 0.1 \mathrm{~mol} / \mathrm{L}$ sodium citrate $\mathrm{pH}$ 6.0). Slides were then cooled to room temperature and washed in distilled water followed by phosphate-buffered saline. Then, specimens were blocked (3 minutes at room temperature) with Power Block Universal Blocking Reagent (BioGenex, Fremont, California). Slides were incubated with the 
primary antibody (anti-ER $\alpha$ antibody, Immunotech, Marseille, France) for 1 hour at room temperature. The Vectastain Elite Mouse IgG ABC-Kit (Vector Laboratories, Burlingame, California) was used for visualization. Sections were stained with 3, 3'-diaminobenzidine (Dako, Glostrup, Denmark) and counterstained with hemalaun. Sections were dehydrated and cover-slipped with Shandon Consul Mount Medium (Thermo Fisher Scientific, Waltham). For the negative control, the primary antibody was replaced by species-specific isotype control antibody. All placentas (40 GDM and 40 controls) were examined. Five representative images per placenta were taken with a digital camera system (JVC, Victor Company of Japan, Yokohama, Japan), and cells were analyzed with a Leitz Diaplan light microscope (Leitz, Wetzlar, Germany). Staining intensity was investigated semiquantitatively by an immune-reactivity score (IRS). This was calculated by multiplying the percentage of stained cells $(0=$ no staining, $1=\leq 10 \%$ of the cells, $2=$ $11 \%$ to $50 \%$ of the cells, $3=51 \%-80 \%$ of the cells, and $4=\geq$ $81 \%$ of the cells) and the different staining intensities (graded as no staining $=0$ [negative], weak staining $=1$, moderate staining $=2$, and strong staining $=3$ ). The intensity and distribution pattern of the immunochemical staining reaction were evaluated by 2 independent blinded observers. ${ }^{29,30}$ In 2 cases $(\mathrm{n}=2.5 \%)$, the evaluation of the 2 observers differed. These cases was reevaluated by both observers together. After the reevaluation, both observers came to the same result. The concordance before the reevaluation was $97.5 \%$.

\section{RNA Isolation, Processing, and Real-Time Polymerase Chain Reaction}

Total RNA was extracted from the decidual tissue using the RNeasy Lipid Tissue Mini Kit (Qiagen, Hilden, Germany) according to the manufacturer's protocol. Quantification and evaluation of the purity of the isolated RNA were carried out with a NanoPhotometer (Implen, Munich, Germany). A ratio of absorbance at $260 \mathrm{~nm} / 280 \mathrm{~nm}^{\sim} 2.0$ was accepted as pure. The reverse transcription was performed with the High Capacity cDNA Reverse Transcription Kit (Applied Biosystems, Weiterstadt, Germany) according to the manufacturer's protocol in a mastercycler gradient (Eppendorf, Hamburg, Germany) for 10 minutes at $25^{\circ} \mathrm{C}, 2$ hours at $37^{\circ} \mathrm{C}, 5$ seconds at $85^{\circ} \mathrm{C}$, and $4^{\circ} \mathrm{C}$ on hold. The real-time polymerase chain reactions (PCRs) were accomplished in optical 96-well reaction microtiter plates covered with optical caps in a volume of $20 \mu \mathrm{L}$, containing $1 \mu \mathrm{L}$ TaqMan Gene Expression Assay 20× (Hs01045840_m1 for VDR, Applied Biosystems), $10 \mu \mathrm{L}$ TaqMan Univeral PCR Master Mix 2x (Applied Biosystems), $8 \mu \mathrm{L} \mathrm{H}_{2} \mathrm{O}$ (DEPC treated DI water, Sigma, Taufkirchen, Germany), and $1 \mu \mathrm{L}$ template. For thermal cycling, an ABI PRISM 7500 Fast (Applied Biosystems) was used for 20 seconds at $95^{\circ} \mathrm{C}$, followed by 40 cycles of amplification for 3 seconds at $95^{\circ} \mathrm{C}$, and 30 seconds at $60^{\circ} \mathrm{C}$. Quantification was performed using the $2^{-\Delta \Delta C T}$ method with $\beta$-actin (Hs99999903_m1) as housekeeping gene. $\beta$-Actin was chosen as it revealed a stable expression in placenta and decidua in normal versus GDM pregnancies.
Table 2. Sequences and Concentrations of Primer and Probes Used for rt-MSP.

\begin{tabular}{lll}
\hline Forward Primer & $5^{\prime}$-ggcgttcgttttgggattg-3' & $9 \mathrm{mmol} / \mathrm{L}$ \\
Reverse Primer & $5^{\prime}$-gccgacacgcgaactctaa-3' & $3 \mathrm{mmol} / \mathrm{L}$ \\
TaqMan probe & FAM 5'-cgataaaaccgaacgacccgacga-3' & $2.5 \mathrm{mmol} / \mathrm{L}$ \\
& TAMRA &
\end{tabular}

Abbreviations: rt-MSP, real-time methylation specific polymerase chain reaction; FAM, 6-carboxyfluorescein; TAMRA, carboxy-tetramethyl-rhodamine.

\section{DNA Extraction and Bisulfite Conversion}

For the extraction of the genomic DNA, $25 \mathrm{mg}$ placental tissues were cut into small pieces and incubated with lysis buffer and proteinase $\mathrm{K}$ (both Macherey-Nagel, Düren, Germany) at $56^{\circ} \mathrm{C}$ overnight. Further steps of DNA isolation were carried out using the NucleoSpin Tissue Kit (Macherey-Nagel) according to the manufacture's protocol. DNA concentrations were measured (Nanodrop; PeqLab, Erlangen, Germany) and $2 \mu \mathrm{g}$ of each DNA sample were treated with the EpiTect Bisulfite Kit (Qiagen, Hilden, Germany) according to the manufacture's protocol. Bisulfite treatment of DNA leads to a conversion of unmethylated cytosine to uracil while leaving methylated cytosine intact.

\section{Estrogen Receptor Promoter Analysis With Real-Time Methylation-Specific $P C R$}

Promoter analysis was performed on a promoter region according to former investigation by our group. ${ }^{31,32}$ In brief, Lapidus et $\mathrm{al}^{33}$ divided the $\mathrm{CpG}$ island of the ER promoter into 6 regions (ER1-ER6) and tested them for methylation and functional relevance in gene expression. The loci ER3, ER4, and ER5 ( -310 and -375 bp upstream of the transcription start site) showed the highest negative correlation between methylation status and ER expression. Comparison of the different primer sets showed the region ER4 of the $\mathrm{CpG}$ island to be most specific for gene expression. ${ }^{31,33}$ The primers and probe used here were published recently ${ }^{34}$ and given in Table 2.

Real-time methylation specific PCR (rt-MSP) was performed to distinguish between methylated and unmethylated promoters: In optical 96-well plates covered with optical caps, the rt-MSP was accomplished in a volume of $25 \mu \mathrm{L}$, containing $2.5 \mu \mathrm{L}$ forward primer (Applied Biosystems), $2.5 \mu \mathrm{L}$ reverse primer (Applied Biosystems), $3 \mu \mathrm{L}$ TaqMan probe (Applied Biosystems), $12.5 \mu \mathrm{L}$ TaqMan Univeral PCR Master Mix 2x (Applied Biosystems), $3 \mu \mathrm{L} \mathrm{H}_{2} \mathrm{O}$ (DEPC treated DI water, Sigma, Taufkirchen, Germany), and $2 \mu \mathrm{L}$ bisulphite-treated DNA. Thermal cycling conditions were 20 seconds at $95^{\circ} \mathrm{C}$, followed by 40 cycles of amplification for 3 seconds at $95^{\circ} \mathrm{C}$, and 30 seconds at $60^{\circ} \mathrm{C}$. Each plate contained patient samples and water blanks as well as positive (MDA-MB-231) and negative controls (Michigan Cancer Foundation-7 [MCF-7] cell line). The ABI PRISM 7500 Fast (Applied Biosystems) was used for the PCR. 


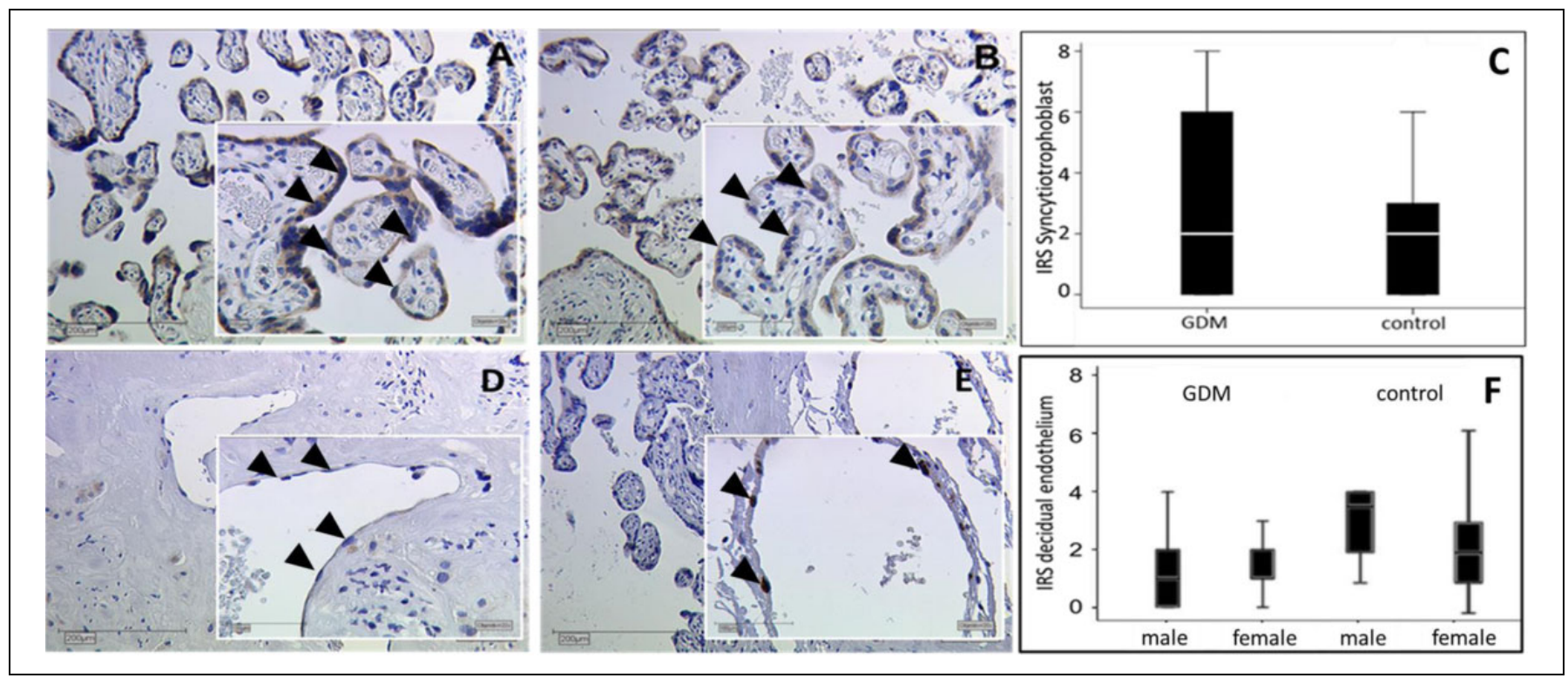

Figure I. Representative slides of immunhistochemical staining for ER $\alpha$ expression in the SCT of GDM positive placentas (A) and controls (B), endothelium of GDM positive decidua (D) and controls $(E)$, both with male neonates. Pictures were taken at a magnification of $10 \times$ and $25 \times$. Arrowheads indicate staining of the ER $\alpha$ in the SCT of GDM (A) and control tissue (B). Arrowheads indicate different staining of ER in cell nuclei of endothelial tissue in the decidua (GDM [D] and control [E]). The immune-reactivity score (IRS) in GDM and control placentas for SCT is shown in the boxplot $(\mathrm{C})$, for endothelium gender specific in boxplot $(\mathrm{F})$. The boxes represent the range between the 25 th and 75 th percentiles with a horizontal line at the median. The bars delineate the 5 th and the 95 th percentiles. Staining was performed in 40 GDM and 40 control placenta. ER $\alpha$ indicates estrogen receptor $\alpha$; SCT, syncytiotrophoblast; GDM, gestational diabetes mellitus. (The color version of this figure is available in the online version at http://rs.sagepub.com/.)

\section{Statistical Analysis}

Statistical analysis was performed using the nonparametrical Mann-Whitney $\mathrm{U}$ signed rank tests and the $t$-test for comparison of the means. Univariate and multiple linear regression models were used to analyze the associations of clinical outcome data with IRS. The models were adjusted for potential and known confounders (maternal age, parity, maternal body mass index (BMI), fetal sex, gestational age, and umbilical artery $\mathrm{pH}) .{ }^{35}$ Statistical significance was assumed at $P$ values $<.05$.

\section{Results}

\section{Immunoreactivity of ER $\alpha$ in Normal and GDM Placenta}

Immunohistochemistry identified $\mathrm{ER} \alpha$ in maternal decidual endothelium, in the SCT, and in the extravillous trophoblasts (EVTs) that invaded into the decidua. In ER $\alpha$ expressing cells, $E R \alpha$ was located in the nucleus and in the cytoplasm. Neither villous macrophage nor feto-placental endothelium was stained for $E R \alpha$.

When immunoreactivies were compared semiquantitatively between normal and GDM placentas using the IRS, SCT (mean IRS 1 vs $1, P=.66$, Figure 1 A-C) showed no expression differences between both the groups. However, in the maternal endothelium, GDM downregulated ER $\alpha$ in decidual vessels, but this GDM effect was only found in pregnancies with male (control IRS 3.5 vs GDM IRS 1, $P=.01$ ) but not female fetuses
(Figure 1D-F). The ER $\alpha$ protein signal was lower in the EVT (mean control IRS 2 vs GDM IRS 4, $P=.011$ ) in GDM when compared to normal pregnancy (Figure 2A-C). In both EVT and $\mathrm{SCT}, \mathrm{ER} \alpha$ immunoreactivity was not different between fetal sexes.

\section{Expression of ER $\alpha$ Messenger RNA in Normal and GDM Decidua}

In order to determine whether increased ER $\alpha$ protein in GDM EVT was a result of increased gene expression, real-time quantitative RT-PCR was performed. Because only EVT but no other placental or decidual cell type showed altered ER $\alpha$ protein levels, decidual tissue containing EVT and decidual stromal cells was separated from villous placental tissue and qPCR was performed. Indeed, expression of ER $\alpha$ messenger RNA (mRNA) was increased about 1.8 -fold in decidua of GDM women when compared to normal controls $(P=.024$; Figure 2D. In parallel to the low abundance of maternal endothelial cells and the high abundance of EVT in decidual tissue, no differences in ER $\alpha$ transcripts related to fetal sex were found in the total tissue.

\section{Methylation of ESR I Promoter in Normal and GDM Placenta}

Altered gene expression may result from promoter methylation changes. To determine whether higher levels of ESR1 mRNA 


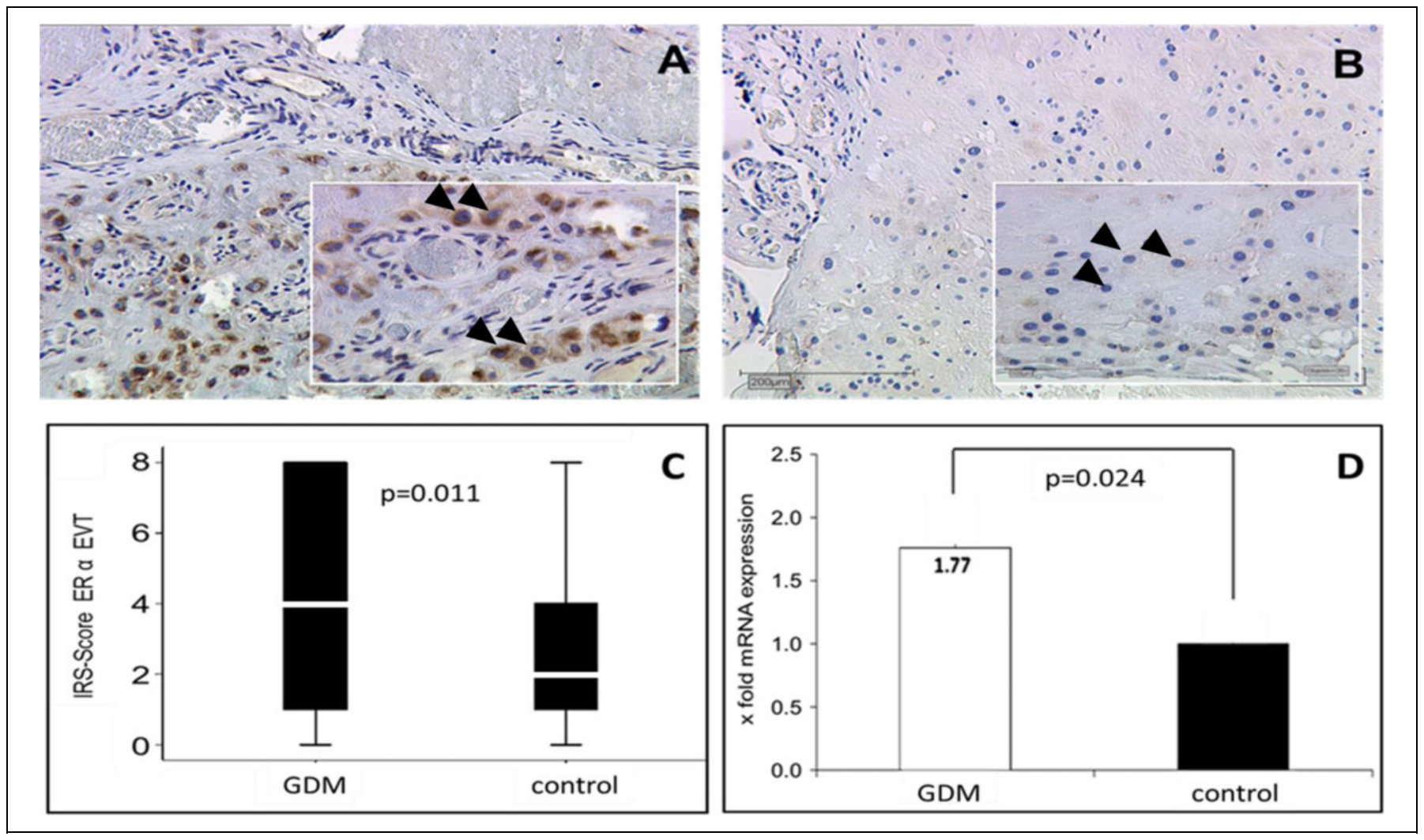

Figure 2. Representative slides of immunhistochemical staining for ER $\alpha$ expression in the EVT of GDM-positive placentas (A) and controls (B). Arrowheads indicate staining of the ER $\alpha$ in the EVT of GDM (A) and control tissue (B). Pictures were taken at a magnification of $10 \times$ and $25 \times$. The immune-reactivity score (IRS) in GDM and control placentas for EVT is shown in the boxplot (C). The boxes represent the range between the 25th and 75th percentiles with a horizontal line at the median. The bars delineate the 5th and the 95th percentiles quantitative RT-PCR: significant $(P=.024)$ upregulation (I.77-fold) of ER $\alpha$ mRNA expression in GDM positive placentas compared to normal controls (D). Staining and quantitative RT-PCR were performed in 40 GDM and 40 control placenta. ER $\alpha$ indicates estrogen receptor $\alpha$; EVT, extravillous trophoblast; GDM, gestational diabetes mellitus; RT-PCR, real-time quantitative polymerase chain reaction; mRNA, messenger RNA. (The color version of this figure is available in the online version at http://rs.sagepub.com/.)

in GDM may result from promoter hypomethylation, we performed rt-MSP for highly methylation sensitive CpG sites in the ESR1 promoter. Decidual tissue of controls revealed ESR1 promoter methylation at this site, whereas in all GDM samples these $\mathrm{CpGs}$ were unmethylated. Methylation was not different between tissue from male versus female pregnancies.

\section{Statistical Confounder Analysis}

As the study groups differed in BMI and birth weight (see Table 1), we analyzed the statistical associations of these potential confounders with $\mathrm{ER} \alpha$ expression. Neither birth weight nor BMI was associated with ER $\propto$ IRS univariately and in addition not after adjusting for other confounders (maternal age, parity, BMI, fetal sex, gestational age, and umbilical artery $\mathrm{pH})$.

\section{Discussion}

In the present study, we identified elevated levels of ER $\alpha$ protein and mRNA in the EVT of women with GDM. Furthermore, this increased expression of ER $\alpha$ in GDM was paralleled by a demethylation of a $\mathrm{CpG}$ in the ESRI promoter, which is essential for transcriptional activity of ESRI.

This is the first study to demonstrate a link between increased ER $\alpha$ levels and ESR1 promoter hypomethylation in placenta in GDM. In line with our results, a previous study showed an upregulation in ER $\alpha$ in decidual GDM trophoblastic tissue. ${ }^{36}$ A later study found no differences in the ESR1 expression in placentas of women with GDM. ${ }^{37}$ However, the absence of difference in ESR1 expression in the latter study may be due to tissue sampling only from the fetal side of the placenta, as we found expression changes only at the maternal side of the placenta. Fetal endothelium was negative for ER $\alpha$ immunostaining, which parallels findings on absent $\mathrm{ER} \alpha$ in human umbilical vein endothelial cells. ${ }^{38}$

Previous studies already demonstrated that the proinflammatory environment of GDM causes promoter demethylation including genes linked to fetal growth and nutrition. ${ }^{18,23,26,39}$ Furthermore, the link between ESR1 promoter demethylation and upregulation of ESRI expression was established in rat trophoblast cells using 5-aza-2-deoxycytidine treatment. ${ }^{40}$ 
The function of ER $\alpha$ in the placenta and in particular in EVT is unknown. In the SCT, the $\mathrm{ER} \alpha$ receptor mediates the estrogenstimulated expression of leptin ${ }^{41}$ and aromatase, ${ }^{42}$ suggesting a role in hormone secretion. In addition, a function in glucose metabolism may be hypothesized since ER $\alpha$ is a key regulator of glucose metabolism in adipose tissue and muscle. ${ }^{1,38,39}$ Extravillous trophoblast is the placental cell type that invades the maternal uterus, anchors the placenta, and remodels uterine vessels to increase blood flow. Thus, the EVT is known as the site of maternal-fetal immune interactions. ${ }^{43,44}$ The role of ER $\alpha$ in EVT function remains to be established, but based on its immunomodulatory function outside pregnancy, ${ }^{45,46}$ it is tempting to hypothesize a similar role also in pregnancy. Insulin resistance is associated with a chronic inflammatory reaction in GDM placenta. ${ }^{47}$ In the light of this proinflammatory environment of GDM and, thus, increased immune modulation, ER $\alpha$ upregulation may be necessary to maintain immune tolerance.

We do not know why only the EVT, but not the SCT, responds to maternal GDM with increased ER $\alpha$ expression. We hypothesize that local decidual factors rather than circulating maternal factors are the underlying reason. Interestingly, our earlier studies showed that in GDM the EVT is the site of strongest change in nuclear receptor expression: While VDR is upregulated in EVT of GDM placentas, ${ }^{48}$ peroxisome proliferator-activated receptor (PPAR) $\gamma$ is downregulated. ${ }^{28}$ Estrogen receptor $\alpha$ physically binds to PPAR $\gamma$ and inhibits its transcriptional activity, ${ }^{49}$ which may further attenuate PPAR $\gamma$ in GDM.

The placenta is regarded as a model to study the effect of the intrauterine environment on epigenetic changes. We found demethylation of a $\mathrm{CpG}$ island in the ESR 1 promoter. However, we have to keep in mind that methylation changes in the placenta may not necessarily reflect events in other target tissues of metabolic programming ${ }^{23}$ as epigenomes can differ between cells and tissues. ${ }^{50}$

Estrogen is a crucial regulator in fat metabolism: Knockout of ER $\alpha$ in mice results in obesity, ${ }^{4}$ and ESR1 expression in adipose tissue is inversely correlated with BMI. ${ }^{51}$ Since BMI is the most significantly different confounder between the GDM and the control group in our study, careful attention was paid in the statistical analysis to identify a potential BMI effect on placental ER $\alpha$ protein expression. This analysis clearly showed that BMI was not associated with placental ER $\alpha$ IRS in univariate analysis $(P=.96)$ nor after adjusting for other possible confounders $(P>.05)$.

A striking finding was the sex-specific effect of GDM on $E R \alpha$ protein expression changes in maternal decidual endothelial cells: While in controls deciduas from pregnancies with male fetuses had higher levels of endothelial ER $\alpha$ expression than deciduas from female pregnancies, this sex difference disappeared in the GDM group. Estrogen was shown to downregulate ESR1 expression in uterine endothelium. ${ }^{52}$ This may explain lower ER $\alpha$ expression in the female decidua. Interestingly, gender differences were found to decline in patients with type 2 diabetes. ${ }^{53}$ Our data reflect this clinical observation: Metabolic deteriorations curb the gender-related differences, since the sex-specific differences in decidual endothelium disappeared in GDM.

In summary, the present study characterizes changes in expression of ER $\alpha$ in the EVT in GDM. In contrast, the SCT showed no changes. Maternal endothelial ER $\alpha$ is subject to sex-specific regulation, which disappears in GDM. Estrogen receptor $\alpha$ promoter hypomethylation in the GDM group may contribute to the reduced ER $\alpha$ levels.

\section{Acknowledgments}

The authors thank Simone Hofmann and Christina Kuhn for excellent technical support.

\section{Authors' Note}

Julia Knabl and Ursula Hiden contributed equally to this work.

\section{Declaration of Conflicting Interests}

The author(s) declared no potential conflicts of interest with respect to the research, authorship, and/or publication of this article.

\section{Funding}

The author(s) received no financial support for the research, authorship, and/or publication of this article.

\section{References}

1. Ropero AB, Alonso-Magdalena P, Quesada I, Nadal A. The role of estrogen receptors in the control of energy and glucose homeostasis. Steroids. 2008;73(9-10):874-879.

2. Barros RP, Machado UF, Gustafsson JA. Estrogen receptors: new players in diabetes mellitus. Trends Mol Med. 2006;12(9): 425-431.

3. Takeda K, Toda K, Saibara T, et al. Progressive development of insulin resistance phenotype in male mice with complete aromatase (CYP19) deficiency. J Endocrinol. 2003;176(2):237-246.

4. Heine PA, Taylor JA, Iwamoto GA, Lubahn DB, Cooke PS. Increased adipose tissue in male and female estrogen receptoralpha knockout mice. Proc Natl Acad Sci U S A. 2000;97(23): 12729-12734.

5. Barros RP, Gustafsson JA. Estrogen receptors and the metabolic network. Cell Metab. 2011;14(3):289-299.

6. Gambino YP, Maymo JL, Perez Perez A, Calvo JC, SanchezMargalet V, Varone CL. Elsevier Trophoblast Research Award lecture: Molecular mechanisms underlying estrogen functions in trophoblastic cells-focus on leptin expression. Placenta. 2012; 33 suppl:S63-S70.

7. Metzger BE, Buchanan TA, Coustan DR, et al. Summary and recommendations of the fifth international workshop-conference on gestational diabetes mellitus. Diabetes Care. 2007;30(suppl 2): S251-S260.

8. Sacks DB, Arnold M, Bakris GL, et al. Guidelines and recommendations for laboratory analysis in the diagnosis and management of diabetes mellitus. Clin Chem. 2011;57(6):e1-e47.

9. Ruchat SM, Houde AA, Voisin G, et al. Gestational diabetes mellitus epigenetically affects genes predominantly involved in metabolic diseases. Epigenetics. 2013;8(9):935-943. 
10. Schwartz R. Hyperinsulinemia and macrosomia. $N$ Engl J Med. 1990;323(5):340-342.

11. Hawdon JM. Babies born after diabetes in pregnancy: what are the short- and long-term risks and how can we minimise them? Best Pract Res Clin Obstet Gynaecol. 2011;25(1):91-104.

12. Barnes-Powell LL. Infants of diabetic mothers: the effects of hyperglycemia on the fetus and neonate. Neonatal Netw. 2007; 26(5):283-290.

13. Desai M, Beall M, Ross MG. Developmental origins of obesity: programmed adipogenesis. Curr Diabetes Rep. 2013;13(1):27-33.

14. Clausen TD, Mathiesen ER, Hansen T, et al. Overweight and the metabolic syndrome in adult offspring of women with diet-treated gestational diabetes mellitus or type 1 diabetes. J Clin Endocrinol Metab. 2009;94(7):2464-2470.

15. Maccani MA, Marsit CJ. Epigenetics in the placenta. Am J Reprod Immunol. 2009;62(2):78-89.

16. Weber M, Hellmann I, Stadler MB, et al. Distribution, silencing potential and evolutionary impact of promoter DNA methylation in the human genome. Nat Genet. 2007;39(4):457-466.

17. Jaenisch R, Bird A. Epigenetic regulation of gene expression: how the genome integrates intrinsic and environmental signals. Nat Genet. 2003;33 suppl:245-254.

18. Bouchard L, Hivert MF, Guay SP, St-Pierre J, Perron P, Brisson D. Placental adiponectin gene DNA methylation levels are associated with mothers' blood glucose concentration. Diabetes. 2012;61(5):1272-1280.

19. Jones L, Hamilton AJ, Voinnet O, Thomas CL, Maule AJ, Baulcombe DC. RNA-DNA interactions and DNA methylation in post-transcriptional gene silencing. Plant Cell. 1999;11(12): 2291-2301.

20. Turner BM. Defining an epigenetic code. Nat Cell Biol. 2007; 9(1):2-6.

21. Banister CE, Koestler DC, Maccani MA, Padbury JF, Houseman EA, Marsit CJ. Infant growth restriction is associated with distinct patterns of DNA methylation in human placentas. Epigenetics. 2011;6(7):920-927.

22. Filiberto AC, Maccani MA, Koestler D, et al. Birthweight is associated with DNA promoter methylation of the glucocorticoid receptor in human placenta. Epigenetics. 2011;6(5):566-572.

23. El Hajj N, Pliushch G, Schneider E, et al. Metabolic programming of MEST DNA methylation by intrauterine exposure to gestational diabetes mellitus. Diabetes. 2013;62(4):1320-138.

24. Ruchat SM, Houde AA, Voisin G, et al. Gestational diabetes mellitus epigenetically affects genes predominantly involved in metabolic diseases. Epigenetics. 2013;8(9):935-943.

25. Ruchat SM, Hivert MF, Bouchard L. Epigenetic programming of obesity and diabetes by in utero exposure to gestational diabetes mellitus. Nutr Rev. 2013;71(suppl 1):S88-S94.

26. Nomura Y, Lambertini L, Rialdi A, et al. Global methylation in the placenta and umbilical cord blood from pregnancies with maternal gestational diabetes, preeclampsia, and obesity. Reprod Sci. 2014;21(1):131-137.

27. Carpenter MW, Coustan DR. Criteria for screening tests for gestational diabetes. Am J Obstet Gynecol. 1982;144(7):768-773.

28. Knabl J, Huttenbrenner R, Hutter S, et al. Peroxisome proliferatoractivated receptor-gamma (PPARgamma) is down regulated in trophoblast cells of gestational diabetes mellitus (GDM) and in trophoblast tumour cells BeWo in vitro after stimulation with PPARgamma agonists. J Perinat Med. 2014;42(2):179-187.

29. Remmele W, Stegner HE. Recommendation for uniform definition of an immunoreactive score (IRS) for immunohistochemical estrogen receptor detection (ER-ICA) in breast cancer tissue. Pathologe. 1987;8(3):138-140.

30. Pavlik R, Wypior G, Hecht S, et al. Induction of $\mathrm{G}$ proteincoupled estrogen receptor (GPER) and nuclear steroid hormone receptors by gonadotropins in human granulosa cells. Histochem Cell Biol. 2011;136(3):289-299.

31. Harder J, Engelstaedter V, Usadel H, et al. CpG-island methylation of the ER promoter in colorectal cancer: analysis of micrometastases in lymph nodes from UICC stage I and II patients. $\mathrm{Br} J$ Cancer. 2009;100(2):360-365.

32. Issa JP, Ottaviano YL, Celano P, Hamilton SR, Davidson NE, Baylin $\mathrm{SB}$. Methylation of the oestrogen receptor $\mathrm{CpG}$ island links ageing and neoplasia in human colon. Nat Genet. 1994;7(4):536-540.

33. Lapidus RG, Ferguson AT, Ottaviano YL, et al. Methylation of estrogen and progesterone receptor gene 5' $\mathrm{CpG}$ islands correlates with lack of estrogen and progesterone receptor gene expression in breast tumors. Clin Cancer Res. 1996;2(5):805-810.

34. Eads CA, Lord RV, Kurumboor SK, et al. Fields of aberrant CpG island hypermethylation in Barrett's esophagus and associated adenocarcinoma. Cancer Res. 2000;60(18):5021-5026.

35. Cogswell ME, Yip R. The influence of fetal and maternal factors on the distribution of birthweight. Semin Perinatol. 1995;19(3): 222-240.

36. Alonso A, Del Rey CG, Navarro A, Tolivia J, Gonzalez CG. Effects of gestational diabetes mellitus on proteins implicated in insulin signaling in human placenta. Gynecol Endocrinol. 2006; 22(9):526-535.

37. Kleiblova P, Dostalova I, Bartlova M, et al. Expression of adipokines and estrogen receptors in adipose tissue and placenta of patients with gestational diabetes mellitus. Mol Cell Endocrinol. 2010;314(1):150-156.

38. Toth B, Saadat G, Geller A, et al. Human umbilical vascular endothelial cells express estrogen receptor beta (ERbeta) and progesterone receptor A (PR-A), but not ERalpha and PR-B. Histochem Cell Biol. 2008;130(2):399-405.

39. Bouchard L, Thibault S, Guay SP, et al. Leptin gene epigenetic adaptation to impaired glucose metabolism during pregnancy. Diabetes Care. 2010;33(11):2436-2441.

40. Oda K, Nishimura T, Higuchi K, et al. Estrogen receptor alpha induction by mitoxantrone increases Abcg2 expression in placental trophoblast cells. J Pharm Sci. 2013;102(9):3364-3372.

41. Gambino YP, Maymo JL, Perez-Perez A, et al. 17Beta-estradiol enhances leptin expression in human placental cells through genomic and nongenomic actions. Biol Reprod. 2010;83(1):42-51.

42. Kumar P, Kamat A, Mendelson CR. Estrogen receptor alpha (ERalpha) mediates stimulatory effects of estrogen on aromatase (CYP19) gene expression in human placenta. Mol Endocrinol. 2009;23(6):784-793.

43. Wallace AE, Fraser R, Cartwright JE. Extravillous trophoblast and decidual natural killer cells: a remodelling partnership. Hum Reprod Update. 2012;18(4):458-471. 
44. Warning JC, McCracken SA, Morris JM. A balancing act: mechanisms by which the fetus avoids rejection by the maternal immune system. Reproduction. 2011;141(6):715-724.

45. Marchetti B, Gallo F, Farinella Z, Romeo C, Morale MC. Luteinizing hormone-releasing hormone (LHRH) receptors in the neuroendocrine-immune network. Biochemical bases and implications for reproductive physiopathology. Ann N Y Acad Sci. 1996;784:209-236.

46. Deb S, Tessier C, Prigent-Tessier A, et al. The expression of interleukin-6 (IL-6), IL-6 receptor, and gp130-kilodalton glycoprotein in the rat decidua and a decidual cell line: regulation by 17beta-estradiol and prolactin. Endocrinology. 1999;140(10): $4442-4450$.

47. Radaelli T, Varastehpour A, Catalano P, Hauguel-de Mouzon S. Gestational diabetes induces placental genes for chronic stress and inflammatory pathways. Diabetes. 2003;52(12): 2951-2958.

48. Knabl J, Huttenbrenner R, Hutter S, et al. Gestational diabetes mellitus upregulates vitamin $\mathrm{d}$ receptor in extravillous trophoblasts and fetoplacental endothelial cells. Reprod Sci. 2015; 22(3):358-366.
49. Alimirah F, Peng X, Yuan L, et al. Crosstalk between the peroxisome proliferator-activated receptor gamma (PPARgamma) and the vitamin D receptor (VDR) in human breast cancer cells: PPARgamma binds to VDR and inhibits 1alpha,25-dihydroxyvitamin D3 mediated transactivation. Exp Cell Res. 2012; 318(19):2490-2497.

50. Schneider E, Pliushch G, El Hajj N, et al. Spatial, temporal and interindividual epigenetic variation of functionally important DNA methylation patterns. Nucleic Acids Res. 2010;38(12): 3880-3890.

51. Nilsson M, Dahlman I, Jiao H, Gustafsson JA, Arner P, DahlmanWright K. Impact of estrogen receptor gene polymorphisms and mRNA levels on obesity and lipolysis-a cohort study. BMC Med Genet. 2007;8:73.

52. Abot A, Fontaine C, Buscato M, et al. The uterine and vascular actions of estetrol delineate a distinctive profile of estrogen receptor alpha modulation, uncoupling nuclear and membrane activation. EMBO Mol Med. 2014;6(10):1328-1346.

53. Kautzky-Willer A, Handisurya A. Metabolic diseases and associated complications: sex and gender matter! Eur J Clin Invest. 2009;39(8):631-648. 